\title{
Violencia en Colombia problema complejo que convoca emergencias desde la educación
}

\author{
América Castillo Bolívar \\ Universidad Católica de Manizales, Colombia \\ americalcb@gmail.com \\ Silvio Cardona González \\ Universidad Católica de Manizales, Colombia \\ scardona@ucm.edu.co
}

\begin{abstract}
RESUMEN
Comprender la violencia en Colombia que deviene del conflicto armado como problema complejo de la educación, en perspectiva de arquitectónicas emergentes para la gestión territorial, como apuestas de humanidad alrededor de tres asuntos cruciales: afectación de la educación rural y urbana por la violencia; desescolarización/desplazamiento forzado; ser maestro es cuestión de héroe, dado que por vía de los Acuerdos de Paz entre el Gobierno Nacional y las Fuerzas Armadas Revolucionarias de Colombia (FARC), las políticas públicas, los programas de gobierno, las demandas y acciones de la sociedad, se han venido generando institucionalidades y expresiones de gobernabilidad y gobernanza, por la importancia de las realidades que viven los territorios de nuestro país, que han soportado a lo largo de cinco décadas el flagelo de la violencia por parte de grupos al margen de la ley. Apuesta abordada metodológicamente mediante la revisión de fuentes explicitas en el Centro de Memoria Histórica, acompañada de reflexiones interpretaciones de los resultados parciales.
\end{abstract}

Palabras clave: Violencia en Colombia, conflicto armado, problema complejo, arquitectónicas de la educación, enfoque territorial.

\section{Violence in Colombia complex problem that demands emergency solutions from education}

\begin{abstract}
Understand the violence in Colombia which comes from the armed conflict as a complex problem of education, in perspective of emerging archetypes for territorial management, as a commitment of humanity around three crucial issues: the influence of rural and urban education by violence; deschooling and forced displacement; since being a teacher is a matter of hero. In relation to this we must mention that through the Peace Agreements between the National Government and the Revolutionary Armed Forces of Colombia (FARC), public policies, government programs, demands and actions of society have generated powerful power constitutional bodies and expressions of governance and governance, for the importance of different realities lived in the territories of our country and that have supported over five decades, the scourge of violence by groups outside the law. A methodologically commitment addressed through the review of explicit sources in Centro de Memoria Histórica (The Historical Memory Centre), accompanied by reflections and interpretations of partial results.
\end{abstract}

KeYwords: violence in Colombia, armed conflict, complex problem, archetypes of education, territorial approach. 
En el afán de comprender esta aldea global, emergen de manera exponencial, crisis que afectan las aristas social, económica, política, axiológica, ideológica, ecológica y organizacional en un medio interno de aparente desorden, de diversidad, no linealidad e incertidumbre.

La violencia en Colombia marcada por el conflicto armado, pone de manifiesto la crisis de la crisis planetaria, y de sus territorios, en perspectiva del nuevo proyecto civilizatorio de la humanidad, que siguiendo a Morin, se podrá interrogar la institucionalidad del Estado, por ejemplo, para el caso de la educación que cimenta sus actuaciones como asunto misional, compromisario con las finalidades del Estado para la prestación de un servicio público de carácter social (gobernabilidad), y que hoy reclama el mundo a la educación para que sea garante de la construcción de las gestas de nuevas humanidades (gobernanzas-arquitectónicas).

Los recientes Acuerdos de Paz en Colombia (noviembre de 2016), convocan la institucionalidad del Estado en períodos de transición, por ejemplo, la justicia en períodos de transición, Morantes (2016), pero, ¿̨cuál transición?; pregunta que anima con los acontecimientos de paz y postconflicto en el mundo aduciendo que «estos hechos fueron objeto de un proceso de sistematización teórica dando origen a los estudios sobre la democratización y contribuyendo a la consolidación de dos subdisciplinas: la transitología y la consolidología ...”

Referentes de enunciación / reflexión / problematización, que se convierten en posibilidad de pensar / actuar la violencia desde la educación para construir una paz estable y duradera (Acuerdo de Paz, noviembre 2016): Desafío para la «Construcción de nuevo país desde la base», fundado alrededor de tres enfoques: Enfoque de derechos y libertades reconocidos en la Constitución Nacional; Enfoque diferencial y de Género, y el Enfoque territorial, teniendo como pilar participación activa de la ciudadanía.

$\mathrm{Al}$ comportarse la educación como un sistema complejo, que se moviliza por su alta capacidad para el análisis, la formación, y la investigación, se podrá convertir en pretexto en despliegue de humanidad, para poder vivir mejor. He aquí desafíos para los sistemas educativos con posibilidades en las que se hagan tejidos en todas las dimensiones en clave de transformación de seres humanos para que con otros modos de percibir, también sea diferente el sentir, el pensar, el actuar y el convivir en una sociedad interrelacionada e interdependiente, en la que puede pregonarse la libertad pero no la independencia, con una pedagogía como disciplina omnicomprensiva y como discurso de la educación compleja, desde donde se comprendan las complejidades como atributos de las realidades de los actores y autores de la educación. 


\section{Contexto teórico}

La violencia es un problema complejo que deviene del conflicto armado, en el que la educación, podrá tener su cometido histórico, por el inmenso potencial de humanidad que podrá desplegar en los individuos, los grupos humanos, las instituciones, en suma, los territorios.

Asunto de facto, que se podrá comprender en el marco de teorías de la paz, el conflicto, el postconflicto, las víctimas, por ejemplo, las teorías sociológicas ${ }^{1}$, como las que plantea Adolfo Rodríguez Bernal (2008, p. 18), al señalar que el «orden e integración social han sido una de las preocupaciones centrales que engendra la dinámica social pronto afectará tanto al orden como a la integración social», y que Giddens (1979)2 al abordar el tema en sociedades avanzadas: «resultan insuficientes y parciales, manteniendo la incapacidad explicativa real de la sociedad, dado que en la actualidad no solo se ha producido un proceso de redistribución del capital sino un verdadero proceso de ámbito marginal» (Rodríguez Bernal, 2008, p. 25).

Una educación que se reconozca legítima en sociedades democráticas, hace suya su misión responsable e ineludible, reconociendo la condición humana en perspectiva transformadora del conflicto. John Paul Lederach, en su libro La imaginación moral, el arte y el alma de construir la paz, plantea «que basado en vivencias de territorios han pasado por tiempos de violencia y están o lograron superar estos acontecimientos a través de una comunidad propositiva», y sus textos, expresa:

Me adentraré en la imaginación moral como la capacidad de imaginar algo anclado en los retos del mundo real, pero a la vez capaz de dar a luz aquello que aún no existe. En referencia la construcción de la paz, está la capacidad de imaginar y generar respuestas e iniciativas constructivas que, estando enraizadas en los cotidianos de la violencia, trascienden y en última instancia rompan los amarres de esos patrones y ciclos destructivos. (Lederach, 2008, p. 57).

No existe una definición única de transformación del conflicto, sin embargo, se acoge la definición que Lederach (2008) propone:

La transformación del conflicto es una forma de visualizar y responder al ir y venir de los conflictos sociales como oportunidades que nos da la vida para crear procesos de cambio constructivo que reduzcan la violencia e incrementen la justicia en la interac-

1 Apuesta académica y de formación de la Escuela Superior de Administración Pública (ESAP), en el marco del «Programa de Fortalecimiento Institucional de la ESAP», en el Eje de Buen Gobierno y Resolución de Conflictos.

2 Giddens, quien revisa el pensamiento de Dahrendorf y Ossowski, insistiendo en la vinculación necesaria de los conceptos de clase, estatus y poder en la compleja estratificación social de las sociedades avanzadas. 
ción directa y en las estructuras sociales, y respondan a los problemas de la vida real en las relaciones humanas. (María, 2007, p. 3).

En este sentido, lograr que la comunidad piense su territorio desde la cotidianidad y actúe en una cultura de paz que transforme su territorio, es algo que realmente no tiene precio ni con el mejor profesional, pues en temas de paz y convivencia se pueden obtener los resultados que arroja la comunidad trabajando por ella misma con actores clave, como lo afirma Lederach (2008, p. 57): «Hay que explorarlos y entenderlos en el contexto de algo que se acerca al proceso artístico, imbuido como está de creatividad, destreza, serendipia, y habilidad artesana».

Al hablar de conflicto armado siempre habrá presencia de violencia. Galtung (1989, p. 3), (citado por Aponte Jaramillo y González Calderón, 2016), expresa:

Las afrentas evitables a las necesidades humanas básicas, especialmente contra la vida, minimizando la atención de estas necesidades a lo que es potencialmente posible. Señala que aquellas necesidades son la supervivencia, el bienestar, la identidad, la representación y la libertad. Las cuales se vulneran a través de violencias directas y estructurales. (p. 3).

Siguiendo a Galtung (1989, p. 3), «las violencias directas atentan contra la necesidad de supervivencia al generar muerte, exterminio, holocausto, genocidio; contra la necesidad de bienestar al producir mutilaciones, acosos, sanciones, miseria; contra la necesidad de identidad al conllevar a desocialización, resocialización, desplazamientos, sometimiento de clases; contra la necesidad de libertad al existir represiones, detenciones y expulsiones».

Galtung (1975), Boutros - Ghali (1992), Chetail (2009) y Rettberg (2003 y 2012), aportan planteamientos sobre el postconflicto, indicando que es el período que explica las causas y la finalización de los conflictos, en tanto:

El uso expansivo del término para abarcar ambos períodos, sin embargo, puede llevar a algunas dificultades conceptuales (Call y Cousens, 2008). De manera concreta, cuando un concepto se expande para abarcar un mayor número de fenómenos corre el riesgo de volverse incapaz de describirlos con suficiente precisión, o de aplicar forzadamente atributos iguales a casos dispares (Sartori, 1970; Steiner, 2008). (Rodríguez de la Rosa \& Palacios Martínez, 2015, p. 7).

Lederach (2008), propone una tesis como punto de partida: «la posibilidad de superar la violencia se forja en la capacidad de generar, movilizar y construir la imaginación moral, y el tipo de imaginación es la que se pone en juego cuando se conjugan y llevan 
a la práctica cuatro disciplinas y capacidades por parte de quienes logran la manera de elevarse por encima de la violencia; imaginación moral que requiere la capacidad de imaginarnos en una red de relaciones que incluya a nuestros enemigos, la habilidad para de alimentar una curiosidad contradictoria que abarque la complejidad sin depender de una polaridad dualista...».

La transformación del conflicto es una forma de visualizar y responder al ir y venir de los conflictos sociales como oportunidades que nos da la vida para crear procesos de cambio constructivo que reduzcan la violencia e incrementen la justicia en la interacción directa $y$ en las estructuras sociales, y respondan a los problemas de la vida real en las relaciones humanas.»

En La imaginación moral: El arte y el alma de construir la paz, Lederach (2008), señala que para romper los patrones de violencia se deben considerar la red de relaciones y el contexto en cual surgen y se manifiestan. Una vez se encuentren los espacios de relación que sustentan la violencia, también se habrá encontrado los espacios para generar cambio social. En el proceso de generación de relaciones, la teoría invita a crear conexiones con personas y grupos que no necesariamente comparten la misma ideología.

\section{Discusión}

Entonces, ¿por qué la violencia es un problema complejo? Tres referentes podrán fundar la comprensión al respecto:

Luengo $(2017)^{3}$, aborda el problema de investigación «cambios de lo real a lo deseado pueden generar nuevos conflictos, que conlleva dos retos prácticos: anticipar lo que va a ocurrir y no sabemos; reconstruir lo que ocurrió y no sabemos»; referencia a Warner Weber (1948), para hacer énfasis en tipo de problemas de investigación: problemas de simplicidad (XVIII-XIX), problemas de complejidad desorganizada (XIXmediados $\mathrm{xx}$ ) y problemas de complejidad organizada ( $\mathrm{xx}$ mediados-XxI), problemas que revelan la presencia de una organización, que implican tratar con las interrelaciones de factores en un todo orgánico), requiere otros procedimientos: análisis de la auto organización, emergencia y no linealidad, revolución científica y discontinuidad con la ciencia normal (o clásica moderna).

3 Enrique José Luengo es académico del ITESO, Universidad Jesuítica de Guadalajara, profesor invitado al programa de Doctorado en Educación de la Universidad Católica de Manizales, Colombia, 2016, 2017, y desarrolla en su cátedra los métodos emergentes en educación, uno de ello, el método de complejidad. 
Morin (1990), acudiendo a la inspiración de sus fuentes, Como el Método: La naturaleza de la naturaleza Las Ideas; El conocimiento del conocimiento; La humanidad de la humanidad; La vida de la vida4.

Nicolesco (2000), con la Carta de Transdisciplinariedad, permitirá el abordaje de problemas complejos como problemas profundos, tema de interés académico que se vienen desarrollando en el doctorado en educación de la Universidad Católica de Manizales, y estudios posdoctorales Educación, complejidad e investigación transdisciplina de la Universidad Simón Bolívar de Barranquilla5.

Se comprenden como problemas complejos al conjunto de ideas, sobre los principios, el método-estrategia y los alcances del conocimiento complejo de lo social, lo educativo en trama con lo ecológico, lo biológico, lo antropológico, lo científico-técnico y tecnológico, que está integrado / articulado en que la educación se constituye en un «todo fenómeno vital. (Vélez, 2017). Si bien, el enfoque territorial, para el abordaje de problemas, denota de entrada una comprensión determinista, es la comprensión compleja de la realidad, la que convoca la mirada multiversa, animada por factores asociados de carácter multidimensional, multirreferencial, y multivariado; desafío de conocimiento que afinca intereses académicos alrededor de vacíos de conocimiento; teórico, en la medida que se reconoce la inexistencia de un sistema de ideas, conceptos y tensiones.

El desafío es pensar la educación en general y la gestión educativa territorial en particular como campos de conocimiento constituido por problemas cruciales, por la capacidad sinérgica que tiene la educación para interactuar con la vida, las ciencias, las humanidades, los territorios; de ahí que, de manera reciente, a la educación se le asigna un atributo de índole inter/transdisciplinar.

Entonces, la complejidad camino de la educación, es el desafío, y podrá ser una opción a los planteamientos que se viene haciendo en este texto, dado que como basamento de la propuesta de Ciurana, Morin y Motta (2003), «sobre la necesidad de educar en la Era Planetaria. El nuevo modo de pensar complejo y las teorías, leyes y principios que le animan, impactan la estructuración de los procesos» (p. 8).

4 En II versión de este artículo se profundizará la figura emergente "problemas complejos», en cuanto problemas profundos, acudiendo a la inspiración de fuentes como las obras de Edgar Morin, en el Método: Las Ideas; El conocimiento del conocimiento; La humanidad de la humanidad; La vida de la vida.

5 Intereses de conocimiento en el marco de: proyecto de investigación docente «Arquitectónicas de la educación a nivel territorial y acuerdos de paz en Colombia; I Fase, 2018 «constitución de un sistema teórico de la educación a nivel territorial en escenarios de paz»; la tesis doctoral de América Leticia Castillo Bolívar «Educación y participación social potenciadoras de desarrollo territorial desde la dialogicidad compleja», grupo ALFA y Doctorado en Educación, Universidad Católica de Manizales, Colombia, y de la investigación posdoctoral «Humanismos Emergentes tejiendo gestión pública territorial», Posdoctorado Universidad Simón Bolívar de Barranquilla, Colombia. 


\section{¿Por qué arquitectónicas de la educación?}

La educación en Colombia, la que ofrece la familia, la calle, lo mediático, la escuela; está construida desde los lenguajes y los estadios del orden, la violencia, las proscripciones, prescripciones y protocolos, sumado a las políticas públicas, las normas, los manuales restrictivos de convivencia, como códigos que inmovilizan, constituyendo así su propia racionalidad que produce más violencia so pena de conquistar la paz, pues aleja a los sujetos de las posibilidades de aprender a vivir entre el conflicto, a través del conflictos y más allá de este.

En esas arquitecturas el saber y el conocimiento no habitan tanto en los saberes de las externalidades de la educación sino en lo intrínseco de las relacionalidades que se tejen en el universo de la educación, la misma que en Colombia está cimentada sobre una estructura epistemológica que denota disyuntivas, disciplinariedades y reduccionismos, que forma cognitivamente alejada de la integralidad, que se organiza desde criterios administrativos capitalistas, localizados, con debilidades en liderazgos políticos, sin vínculos estrechos entre los avances técnicos y los desarrollos sociales, sin comprensiones de las desigualdades sociales y con acentos culturales en tiempos de interculturalidades.

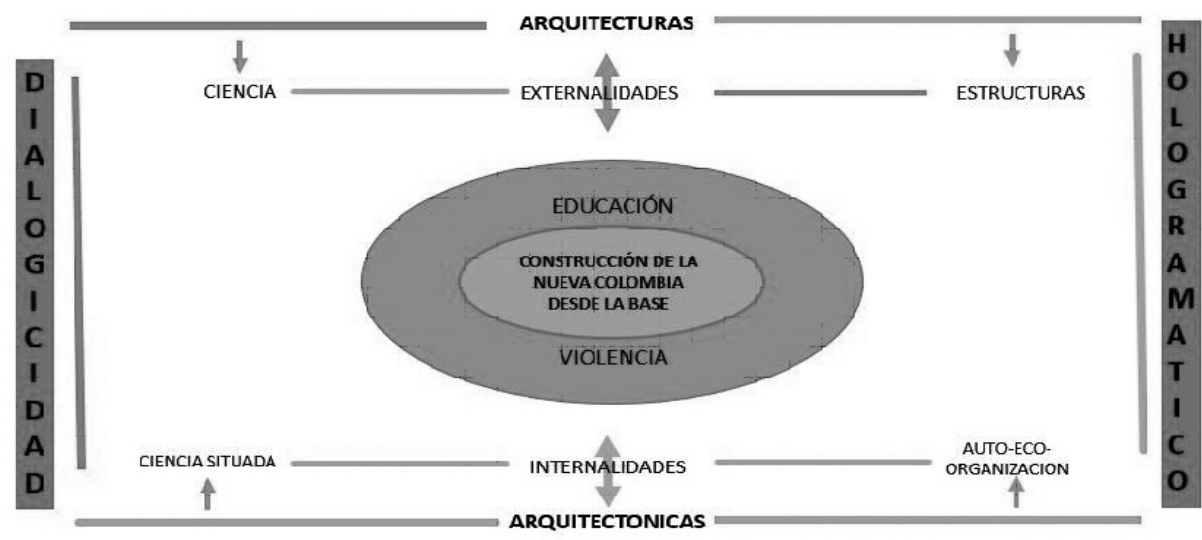

RETROCURSIVIDAD

Figura 1: Elaborado por Silvio Cardona González (noviembre 2018)

Una cosmovisión nueva que deviene de los cambios conceptuales dirigiendo la proa visionaria de los investigadores a la construcción de nuevas/otras preocupaciones estratégicas, orientados en el sentido de lo evolutivo de los cambios y de las dinámicas del caos y el orden, en un mundo de lo educativo que se compone sistémicamente de otros mundos con lógicas distintas que permiten comprensiones de la unidad en la diversidad y que con los rasgos de la hipercomplejidad se moviliza entre lo dialógico, lo recursivo y lo hologramático. 
En clave de humanidad sostendríamos que los actores de la educación -todos- son sujetos privilegiados en la naturaleza que se movilizan entre las complejidades, el orden y el caos, por lo que se implementará el modelo de la teoría del caos, un modelo que en sus dinámicas y hasta en sus determinismos permite tratamientos investigativos con fenómenos cambiantes como la educación denotando evolución en esas coordenadas señaladas para la educción territorial.

Las arquitectónicas del sistema educativo colombiano asumido como el cruce fértil de los escenarios en que se despliega lo transformativo de la educación, se cruzarán con las ciencias de la complejidad como una posibilidad de abordar holísticamente las realidades con componentes multidimensionales que hacen la movilización por los ámbitos político, económico, geográfico, sociológico, psicológico, jurídico, ético y cultural en un entramado interdependiente e interretroactivo de modo hologramático en cruce de las partes y el todo y de éste con aquellas.

\section{BALANCE DEL CONFLICTO ARMADO}

1958

2018
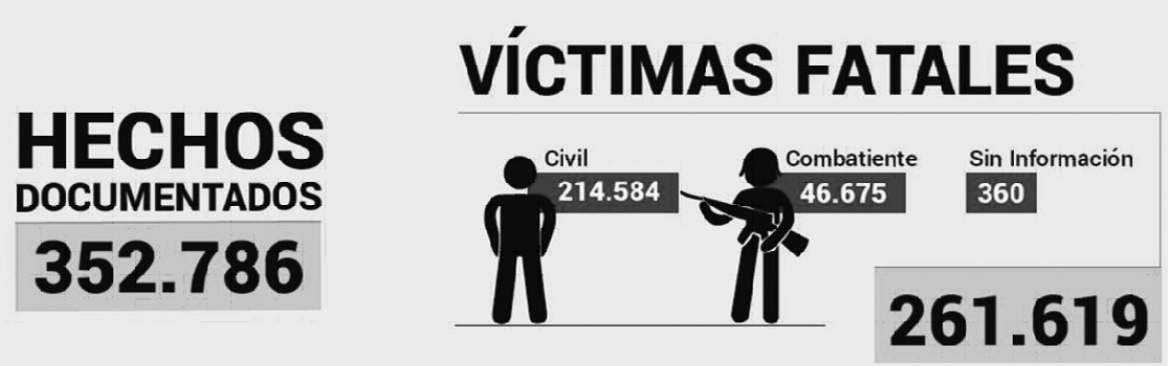

Figura 2: Centro de Memoria Histórica (Colombia, 2018)

En el plano normativo colombiano, se encuentra otra definición para el término 'víctimas', establecido por la ley 1448 de 2011, en el artículo 3, donde se les considera a:

Aquellas personas que individual o colectivamente hayan sufrido un daño por hechos ocurridos a partir del $1^{\circ}$ de enero de 1985 , como consecuencia de infracciones al Derecho Internacional Humanitario o de violaciones graves y manifiestas a las normas internacionales de Derechos Humanos, ocurridas con ocasión del conflicto armado interno. (Congreso de la República, 2011).

De igual manera, en los decretos-ley 4633, 4634 y 4635 de 2011, se reconoce la diversidad cultural que existe alrededor de las víctimas del conflicto armado y, a su vez, 
dictan medidas de asistencia, atención, reparación integral y restitución de tierras para las comunidades y pueblos indígenas, comunidades negras, afrocolombianas, raizales, palenqueras y el pueblo Rrom o Gitano.

Existen infinidad de aspectos importantes cuando se trata de la dialogicidad entre violencia y educación a través de los procesos de paz, y lo digo porque los acuerdos de paz firmados el pasado mes de noviembre del 2016, tras cuatro años de diálogos con la guerrilla de las FARC (Fuerzas Armadas Revolucionarias de Colombia), dan sus frutos y se llegan a acuerdos políticos, económicos, sociales y educativos ${ }^{10}$.

Afectación de la educacion rural y urbana por la violencia

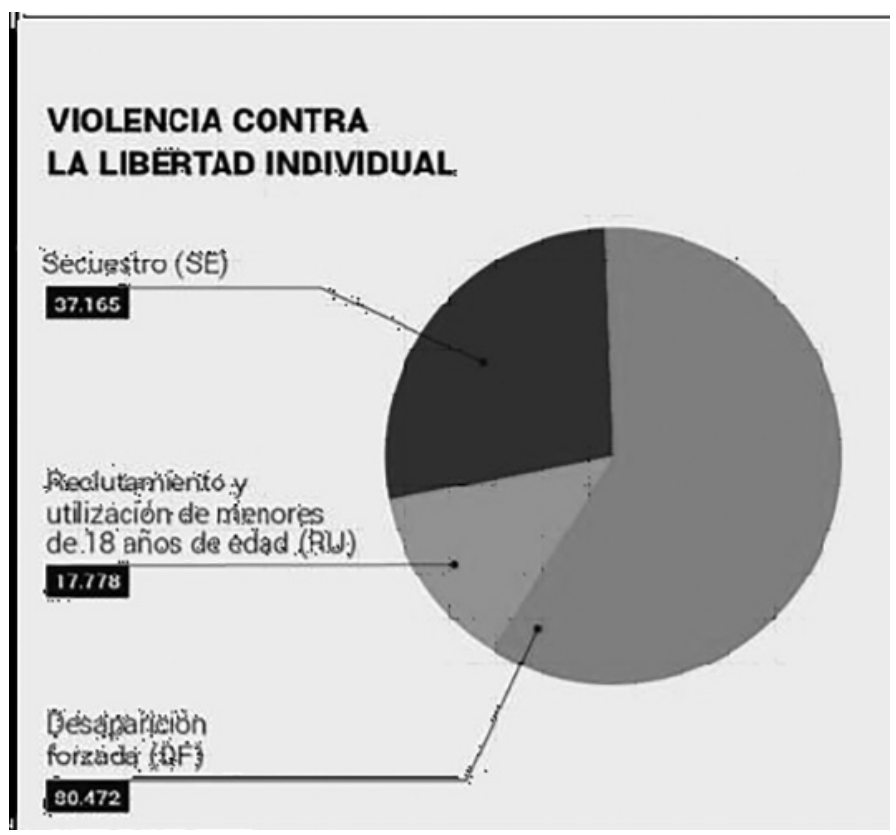

Figura 3: Centro de Memoria Histórica (Colombia, 2018)

Si bien es una de las guerras más antiguas del mundo, tras 58 años de lucha entre el gobierno y la guerrilla de las FARC, pero también del ELN (Ejército de Liberación Nacional), EPL(Ejército Popular de Liberación), M19 (Movimiento del 19 abril), MAS (Muerte a Secuestradores), de los paramilitares (grupo armado ilegal de extrema derecha o AUC), de las bacrim (bandas criminales), de las barreras invisibles y del narcotráfico; todos grupos armados fuera de la ley con altos alcances sobre la población civil, llegar a firmar mínimamente un acuerdo con uno de ellos ha sido de gran valor para el país y para el mundo entero.

Es sabido, que los alcances a nivel educativo entre las áreas rurales y los sectores urbanos se han mostrado diferentes por las precariedades de acceso, de personal capa- 
citado y de infraestructura entre muchos otros; pero cuando se tiene todos los grupos criminales mencionados alrededor o dentro de las instituciones se hace más complicada la educación.

En lo rural la falta de asistencia es un tema importante, ya que los nińos y las familias se sienten amenazadas y con miedos, pues la forma de operar es robarlos a la guerra desde niños, matarlos, violarlos o ponerlos a sus servicios, pero fuera y lejos de sus familias, haciéndolos pasar por desaparecidos. Según la Oficina del Alto Comisionado de Naciones Unidas para los Derechos Humanos en Colombia ${ }^{11}$, en el año 2002 había 14000 niños, niñas y jóvenes vinculados al conflicto armado (FARC, ELN y AUC); el informe del año 2003 de Human Rights Watch ${ }^{12}$ señalaba que eran 11.000. Por su parte UNICEF afirma que Colombia es el tercer país del mundo con mayor número de niños soldados, luego de Congo y Liberia ${ }^{13}$. En cuanto a la cantidad de nińos, niñas y jóvenes en cada grupo armado, hay aproximados que demuestran que la mayoría han hecho parte de las FARC, seguido por los paramilitares y luego el ELN:

Los grupos armados ilegales de los que procedían la mayoría de los niños, niñas y adolescentes desvinculados eran: las Fuerzas Armadas Revolucionarias de Colombia FARC (54,8\%), seguido de las Autodefensas Unidas de Colombia - AUC ( 22,3\%), el Ejército de Liberación Nacional. ELN (15,1\%), las Autodefensas Campesinas del Casanare. ACC (9,3\%), el Ejército Revolucionario del Pueblo ERP (1,1\%), y otra serie de organizaciones que por su escasa representación en la muestra (generalmente un caso) se agruparon en la categoría Otros y que constituyen en su conjunto el 1,9\% de la población sujeto de estudio ${ }^{14}$

Y las cifras más actuales según CNMH, Bases de datos, Observatorio de Memoria y Conflicto, fecha de corte: 15/09/2018. Nos habla de alrededor de 17 mil nińos o menores de 18 ańos involucrados en la guerra. Los cuales fueron reclutados de múltiples formas y afectaron no solo zonas rurales sino urbanas.

Además, la falta de apoyo del estado en ciertos sitios es cruel y no tienen más remedio que dedicarse a actividades ilegales como el cultivo de coca, convirtiendo dichos escenarios en violentos y en medio de una guerra que pasa de la moral a la supervivencia.

En los sectores urbanos, el panorama cambia, debido a que, si bien dichos grupos guerrilleros no están entrando a las escuelas, los demás como las bacrim, el narcotráfico y las barreras invisibles, les demarcan el territorio para que no pasen o no hagan ciertas actividades normales del ser humano, de lo contrario si no hacen caso lo pagan con sus vidas. Entonces la cantidad de nińos muertos y desplazados por estas situaciones entre pueblos o entre los mismos barrios de las ciudades es frecuente, impidiendo un arraigo por su territorio y sus costumbres. 
Pero: ¿cómo es que se afecta la educación rural y urbana? Pues muy sencillo, la calidad no es igual debido a las desigualdades de los territorios, donde los maestros no quieren o no pueden ni llegar, pero además las necesidades básicas no se cubren como la energía y esto son impedimentos para que la educación en dichas zonas sea de calidad o por lo menos medianamente igual a la de las ciudades. De otro lado las inclemencias de la guerra impiden que los niños asistan mientras los grupos armados se encuentren en enfrentamientos porque son los que sufren por los caminos que deben de recorrer.

Normalmente las personas que están en dichas zonas rojas (peligrosas) o de difícil acceso, son las que terminan desplazándose hacia otras regiones perdiendo el arraigo por su tierra, sus pocos enseres pero sobre todo la oportunidad de vivir en su sitio y de educarse en el mismo, pasando este tema educativo a otro plano menos importante.

En las zonas urbanas si es cierto que cuentan con mejores oportunidades, mejores instalaciones, mejores docentes y centros de atención desde la primera infancia, las dificultades son iguales o peores según como se mire. Pues los padres en su común denominador no son educados profesionalmente y se rebuscan el diario (en barrios de bajo estrato), así que los hijos terminan prostituyéndose por pesos a los bandidos del narcotráfico, pero también los grupos armados ilegales quienes amedrantan a las personas de otros estratos a pagar dádivas por el derecho al trabajo. Haciendo que esto sea una problemática para no contar con niños educados ni asistiendo a escuelas.

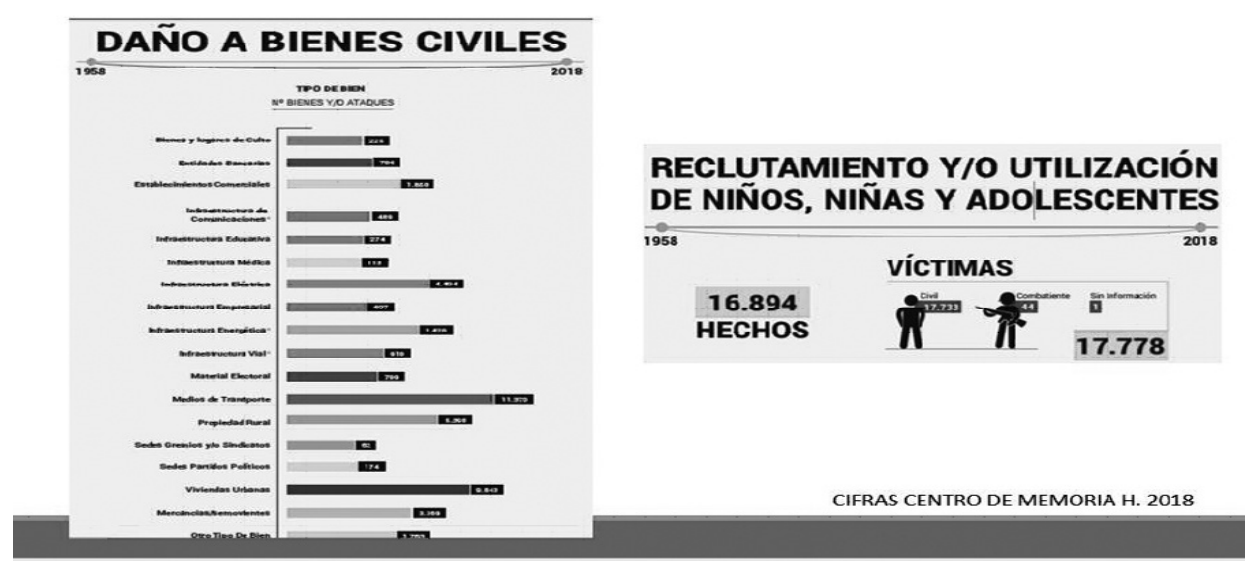

Figura 4: Centro de Memoria Histórica (Colombia, 2018)

\section{Ser maestro es una profesión de héroes}

Las escuelas con mucha frecuencia son blancos militares y se encuentran innecesariamente en sitios de alto riesgo como cerca de bases militares, donde la vida de todos está en alto riesgo. La ONU y otro tipo de organizaciones han datado esto, pero además la 
GCPEA (Coalición Global de Protección de Ataques a la Educación) tiene variedad de estadísticas acerca de los ataques y donde es bastante enternecedor que las agresiones después de la firma del acuerdo se han intensificado.

Por ejemplo, el informe del año 2010 manifiesta la muerte de 90 maestros entre el 2006 y 2008, pero además como la desaparición forzada de maestros y sindicalistas sigue en aumento. Los ataques deliberados e indiscriminados en escuelas y universidades hacia los estudiantes y el personal docente se han incrementado en los últimos cinco años, según la edición del informe de 2018 publicado el 9de mayo, por la Coalición Global para Proteger a la Educación de Ataques (GCPEA). El informe Educación bajo ataque 2018 identifica más de 12700 ataques desde 2013 hasta 2017. Inclusive el último informe del Centro de memoria Histórica dice que durante los 60 ańos de guerra, fueron atacadas 274 infraestructuras educativas, más cantidad que infraestructuras políticas, así que ese número deja mucho que pensar; la lucha era política o era educativa? $\mathrm{O}$, de quién era en realidad.

Un informe de la Unesco ${ }^{15}$ da a conocer cómo Colombia se ubica en países violentos contra maestros como Iraq, Gaza, Nepal y Tailandia, y los maestros universitarios no son la excepción. Así que no se si llamarlo como lo hace María Emma Wills 'La nueva vieja guerra'. Por tanto, la labor docente se ve reducida a estar por los corredores de oficinas cumpliendo un horario, más no en las aulas educando a nuestros niños colombianos que de manera indirecta se afectan por la no asistencia de los mismos y quedan a merced de los grupos armados y de un futuro incierto.

Entonces, es de héroes, es estar salvando a los ciudadanos como lo muestran las grandes pantallas del mundo? O será más bien de héroes tener que luchar con las realidades del común contra las personas que suelen rebelarse contra el gobierno afectando a los más indefensos, robando su niñez y sus sueños de ser alguien en la vida, como si ya no lo fueran desde que nacieron.

La profesión de ser maestros en Colombia, es una labor digna, que aunque mal paga y mal remunerada no se contará con un sueldo que pueda compensar todo lo que se hace en un ańo dentro de las academias, pero peor aun cuando el gobierno no pone las mejores condiciones y se dedica a un asistencialismo mediático y temporal, que termina solucionando los problemas durante un período de gobierno.

La gran mayoría de las acciones de los grupos armados, provoca en las personas bien sea campesinas o citadinas un desplazamiento del lugar de origen, donde tiene pertenencias y son alguien en dichos puntos geográficos, con animales, cultivos y vida escolar y social; pero cuando se dan las manifestaciones de violencia y logran salir ilesos de dichos ataques, las personas por temor huyen a sitios lejanos, donde las costumbres y usos son diferentes, dejando todo atrás y engrosando las listas de desplazamiento pero de pobreza, de indigencia y por obvias razones de bajos niveles educativos, los cuales hacen que los niños pasen de colegio en colegio o que deserten definitivamente para 
ayudar en labores hogareńas mientras cuidan hermanitos menores y sus padres o familiares cercanos trabajan de manera informal en vías.

Desescolarizacion/desplazamiento forzado

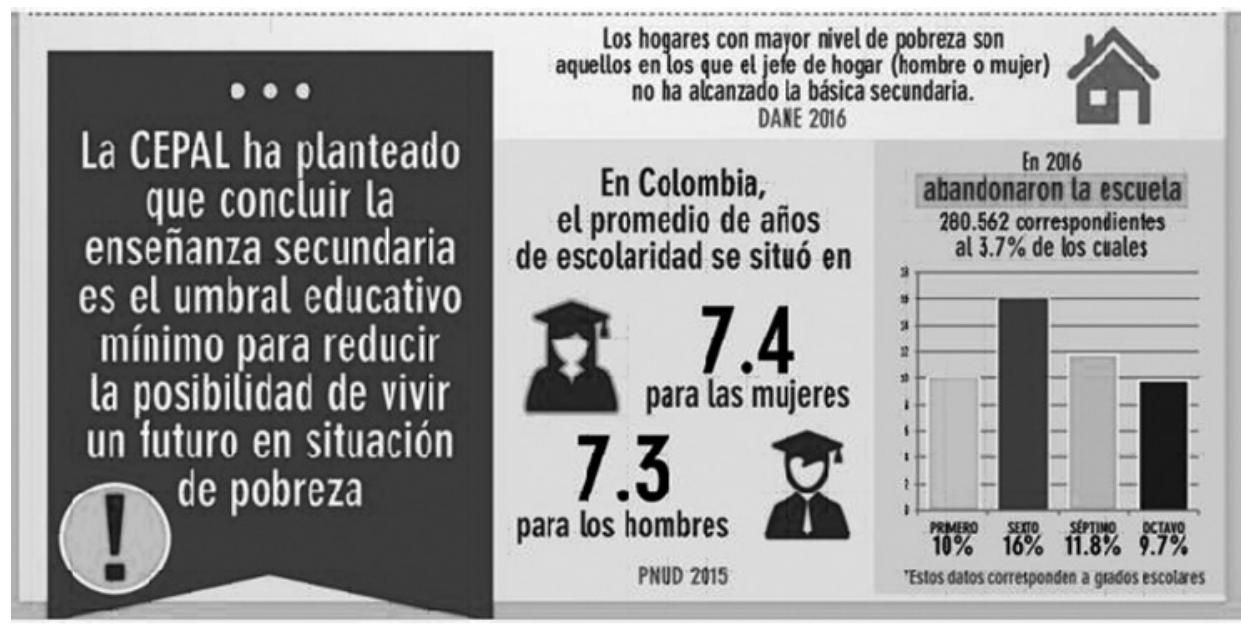

Figura 5: Centro de Memoria Histórica (Colombia, 2018)

Por tanto, la desescolarización es un tema que viene con la violencia, y aunque sin lugar a duda se ha combatido fuertemente las bajas tasas de abandono, repitencia y deserción escolar, no es un tema ajeno y que afecta a las familias a corto plazo pero al país a largo plazo dejaría de contar con personas adultas sin educación formal que los lleve a l obtención de mejores empleos.

A la fecha (noviembre de 2018), según el periódico El País, dice que Colombia tiene $5.8 \%$ de analfabetismo en personas mayores de 15 años, y que este año podría ser declarada como un país con este tema erradicado. Pero también se conoce que la población analfabeta está en las zonas violentas que a causa de la guerra sus estudios quedaron parados, pero además que el $70 \%$ de los desmovilizados son analfabetas y que esto no fue prioridad en sus vidas, pero actualmente con los planes para ponerle fin a la guerra esto es prioritario.

Finalmente, es vital recalcar que a la actualidad existen datos muy fehacientes como los entregados o publicados por el centro de memoria histórica de Colombia, el cual tiene una actualización del mes de septiembre de 2018, al cual pertenecen las gráficas usadas para una mayor comprensión de los lectores.

Por tanto, al firmar dicha paz tan anhelada, se habla entonces de crear políticas publicas acordes a las necesidades de los afectados, de los partícipes, de la sociedad en general y así lograr una reconciliación que empuje a la comunidad en general a salir de tanto dolor y sufrimiento. 
El acuerdo de paz, es entonces, un documento que tiene 297 páginas, de las cuales se habla de educación en 27 oportunidades y 12 veces de pedagogía (Revista Semana, 26 de septiembre 2016). Y dichas palabras se ubican en otros subtemas como:

Educación y pedagogía para la reinserción de las guerrillas a lo largo de 23 veredas y reciban educación con programas que ayude a la formación laboral y culminar o nivelar la primaria, la secundaria y la media académica.

Pedagogía para dignificar el campo, siendo de los más afectados con la guerra, exigen educación de calidad, con modelos flexibles, de alta cobertura e infraestructuras dignas.

Pedagogía para la reconciliación y la paz, la idea es crear un consejo de reconciliación y convivencia, que permita estar en un mismo espacio, excombatientes y ciudadanos, pero sobre todo desde las cátedras educativas de paz y ciudadanía dictadas desde las instituciones educativas.

Finalmente, diseño de programas especiales que permitan la difusión y comprensión de los acuerdos en todos los sectores y niveles educativos, con un único objetivo que queden en el Plan Nacional de Educación.

\section{Conclusiones}

Visualizar y responder al ir y venir de los conflictos como contextos vitales para la transformación del conflicto, asumiéndolo como oportunidad de crecimiento y un motor de cambio que da respuesta a las necesidades humanas. .

Hoy se necesita un proceso de construcción de ciudadanía, que es la forma más adecuada para que desde la participación democrática, se puedan ejercer los derechos humanos y se conviertan en una realidad en todos los contextos de la vida y la puesta en práctica desde las comunidades.

Hacer vida la Constitución Política de Colombia 1991, los derechos humanos de primera, segunda y tercera generación, de tal manera que permita respetar los derechos a la vida, la paz como obligación y como derecho, la democracia, la convivencia, la ciudadanía, el pluralismo, el ejercicio de la tolerancia y la libertad.

Incentivar gestiones territoriales en el marco de las exigencias, protocolos y acuerdos que deviene de la Declaración Universal de los Derechos Humanos, el Derecho Internacional Humanitario, el Derecho Penal Internacional y desde las libertades fundamentales, se desarrollarán capacidades, actitudes, aptitudes, conocimientos necesarios para que hombres y mujeres ejerzan plenamente su ciudadanía en los diferentes contextos, que redunden acciones concretas en pro del respeto, la defensa de la vida-.

Se requiere entonces de un conocimiento que facilite a quien lo construye y a quien lo utilice el darse cuenta de lo que significa ser ciudadano comprometido con sus entornos, la sociedad, el estado social de derecho. 
Ser garantes de las subjetividades política, que requieren despliegues de humanidad, que se refleja en índices de equidad y la justicia social, armonía, convivencia, que llevan al ejercicio de una ciudadanía planetaria, direccionados hacia la construcción de paz.

Convoca así mismo la necesidad de comprender la violencia como desafío de paz imperfecta», reflejo de los criterios de pertinencia y contextualización del problema que es de naturaleza y desafío territorial.

Se perfila así la necesidad de pensar / indagar / otros planos de comprensión compleja de la educación a nivel territorial, que se tejan por conocimientos complejos, que generen posibilidades de comprender la nueva institucionalidad en períodos de transición, en cuanto dinámicas como posibilidad de relaciones / relacionamientos vitales del bucle Educación / Estado-Sociedad / Territorio, que se debaten en movimientos globales / locales convocando las "partes» y el «todo», para hacer vida el ejercicio de responsabilidad pública con la formación humana.

Construir la paz es más difícil que llegar a un acuerdo entre las partes en conflicto. Será una tarea de toda la sociedad civil y no de unos pocos. La educación en su más amplio sentido tendrá el papel de gestora de paz, educación individual y social, una verdadera educación del ser humano más que capacitación eficiente.

\section{Referencias}

Aponte , J. A., \& González, D. (2016). Aproximación al concepto de posconflicto: una mirada desde la paz transformadora. Revista Mundo Jurídico, 1(2), 1-13.

Bueno, M. A. (Mayo-Agosto de 2017). Políticas públicas de reconciliación. Un reto posible en la construcción y la sostenibilidad de la paz en Colombia. Revista Análisis Politico, 30(90), 3-24.

Cardona, S., \& Gómez, M. M. (2006). Redes de gestión como factores asociados al desarrollo institucional de las administraciones públicas locales. Manizales, Colombia: Escuela Superior de Administración Pública.

Castrillón, L., Riveros, V., Knudsen, M. L., López, W., Correa, A., \& Castañeda, J. G. (2018). Comprensiones de perdón, reconciliación y justicia en víctimas de desplazamiento forzado en Colombia. Revista de Estudios Sociales, 63, 84-98.

Cerrá, R. J. (2015). Iniciativas y prácticas de paz desde lo local: la paz en concreto. En F. C. Democrática, Seminario los procesos de paz en Colombia: experiencias y propuestas desde las ciudades regiones (págs. 78-91). Bogotá, D.C., Colombia: Fundación Cultura Democrática (FUCUDE).

Congreso de la República (2011). Ley 1448: "por la cual se dictan medidas de atención, asistencia y reparación integral a las victimas del conflicto armado interno y se dictan otras disposiciones». Bogotá, D.C., Colombia: Imprenta Nacional. 
De Roux, F. (2018). La audacia de la paz imperfecta (Primera ed.). Bogotá, D.C., Colombia: Editorial Grupo Planeta.

Departamento Nacional de Planeación (2016). Informe al Congreso Juan Manuel Santos. Presidencia de la República, Bogotá, D.C.

Gómez, A. P. (Enero-marzo de 2015). Una apuesta educativa para América Latina: educación para la paz. Revista Latinoamericana de Estudios Educativos (México), XLV(1), 17-62.

Grupo de Investigación en Desarrollo Territorial, Paz y Posconflicto (GIDETEPP). (2012). Hermes: Sistema de Información de la Investigación Universidad Nacional de Colombia. Recuperado el 13 de Marzo de 2018, de http://www.hermes.unal.edu.co/pages/Consultas/Grupo.xhtml;jsessionid=78E7DC4 6408A226B796617A896C6B06A. tomcat4?idGrupo=2090\&opcion=1

LEDERACH, J. P. (2008). La imaginación moral: el arte y el alma de construir la paz (Primera ed.). Bogotá, D.C., Colombia: Editorial Norma S.A.

Loaiza de la PAVA, J. A. (2016). "Niños, niñas y jóvenes constructores-as de paz». Una experiencia de paz imperfecta desde la potenciación de subjetividades políticas. Centro de Estudios Avanzados en Niñez y Juventud (CINDE). Manizales: Universidad de Manizales.

Morin, E. (1992). Las ideas: su hábitat, su vida, sus costumbres, su organización. Anaya-Spain, (4), $216-247$.

Morin, E. (1997). Cap. I El todo es más que la suma de las partes. El método I. Madrid:

Morin, E. (2003). La humanidad de la humanidad: la identidad humana (Vol. 5). Anaya-Spain. CÁTEDRT.

Morin, E., Ciurana, R. E., Motta, R. (2003). Educar en la era planetaria. Gedisa.Barcelona. Morin (2004), Del objeto al sistema; de la interacción a la organización.

Morin, E., \& Delgado, C. (2016). Reinventar la educación. Abrir caminos a la metamorfosis de la humanidad. Ciudad de México: Multiversidad Edgard Morín.

Miguelez, M. M. (1997). El paradigma emergente hacia una nueva teoría de la racionalidad cientifica. México: Trillas, S.A.

Pineau, G. (2009). Estrategia universitaria para la transdisciplinariedad y la complejidad. Revista Visión Docente Con-Ciencia, 8(48), 5-17.

Muñoz, F. A. (2004). Paz imperfecta. En M. López Martínez, Enciclopedia de paz y conflictos (Especial ed., Vol. II, pág. 1227). Granada, España: Editorial Universidad de Granada.

PAChón, W. (2018). Inclusión social de actores del conflicto armado colombiano: retos para la educación superior. Revista Desafios, 30(1), 279-308.

Rodríguez de la Rosa, L. G., \& Palacios Martínez, S. N. (2015). Paz, posconflicto y sus elementos característicos. Un acercamiento conceptual. Trabajo de grado, Universidad de San Buenaventura, Facultad de Derecho y Ciencias Políticas, Santiago de Cali.

VAnier, M. (2010). El poder de los territorios (Vol. 2). París, Francia: Editorial Anthropos. Vargas Velásquez, A. (19 de Febrero de 2018). La audacia de la paz imperfecta. El Colombiano. 